\title{
Using Simulation Training to Promote Nurses' Effective Handling of Workplace Violence: A Quasi-Experimental Study
}

\author{
Jin-Lain Ming ${ }^{1, *}$, Hui-Mei Huang ${ }^{1}$, Shiao-Pei Hung ${ }^{1}$, Ching-I Chang ${ }^{1}$, Yueh-Shuang Hsu ${ }^{1}$, \\ Yuann-Meei Tzeng ${ }^{1}$, Hsin-Yi Huang ${ }^{2}$ and Teh-Fu Hsu ${ }^{3}$ \\ 1 Department of Nursing, Taipei Veterans General Hospital, No.201, Sec. 2, Shipai Rd., Beitou District, \\ Taipei City 11217, Taiwan; hmhuang2@vghtpe.gov.tw (H.-M.H.); sphong@vghtpe.gov.tw (S.-P.H.); \\ Cichang2@vghtpe.gov.tw (C.-I.C.); ys_hsu@vghtpe.gov.tw (Y.-S.H.); ymtzeng@vghtpe.gov.tw (Y.-M.T.) \\ 2 Department of Biostatistics Task Force, Taipei Veterans General Hospital, No.201, Sec. 2, Shipai Rd., \\ Beitou District, Taipei City 11217, Taiwan; sweethsin509@gmail.com \\ 3 Emergency Department, Taipei Veterans General Hospital, No.201, Sec. 2, Shipai Rd., Beitou District, \\ Taipei City 11217, Taiwan; tfhsu@vghtpe.gov.tw \\ * Correspondence: jlming@vghtpe.gov.tw; Tel.: +886-2-2875-7808
}

Received: 29 June 2019; Accepted: 25 September 2019; Published: 28 September 2019

\begin{abstract}
Background: Workplace violence in the health care sector has become a growing global problem. Research has shown that although caregivers comprise a high-risk group exposed to workplace violence, most of them lacked the skills and countermeasures against workplace violence. Therefore, through a quasi-experimental design, this study aimed to investigate the effectiveness of situational simulation training on the nursing staffs' concept and self-confidence in coping with workplace violence. Methods: Workplace violence simulation trainings were applied based on the systematic literature review and the conclusions from focus group interviews with nursing staff. Data were obtained from structured questionnaires including: (1) baseline characteristics; (2) perception of aggression scale (POAS); and (3) confidence in coping with patient aggression. Results: The results revealed that training course intervention significantly improved the nursing staffs' self-perception and confidence against workplace violence $(p<0.001)$. Conclusions: The "simulation education on workplace violence training" as the intervention significantly improved the workplace violence perception and confidence among nursing staffs in coping with aggression events.
\end{abstract}

Keywords: workplace violence; simulation training; nurse

\section{Background}

\subsection{Workplace Violence among Health Care Workers}

Physical violence, injury, harassment, and bullying at workplaces are not new phenomena worldwide [1]. Nelson, a leading expert on workplace violence, has pointed out that in both developed and undeveloped countries, the rate of violence and abuse towards health workers was four times higher than that towards other occupational groups [2]. In particular, health workers directly facing the patients and public are common victims of workplace violence. Prior research has shown that female nurses were the most frequent group at high risk of workplace violence [3-5]. An increasing incidence of workplace violence in the health environment has raised a great concern among workers and employers [3,4,6,7]; the incidence of violent episodes has been recognized as a major health priority by the World Health Organization (WHO) and the International Council of Nurses (ICN) [8] and a "zero tolerance" policy for workplace violence was then proposed [9]. Based on the experiences 
from prior studies, identifying the factors which lead to workplace violence, could help facilitate documenting and reporting violent episodes as well as developing effective prevention strategies to protect nursing staff from exposure to workplace violence $[10,11]$.

\subsection{Workplace Violence Training Program and Simulation Teaching}

In terms of developing well-designed workplace violence training programs for health care workers, the most significant gap in content was the lack of attention to risk assessment and policy for workplace violence. Simulation is defined as learning activities in a range of mimicked real-world clinical environments, through role play or immersive devices, to reach the goal of demonstration procedures, decision-making, and critical thinking [12-14]. Simulation education is more and more frequently used in nursing education and is considered as an effective clinical teaching strategy [14]. As the importance of simulation training has grown, many studies have demonstrated the effectiveness of simulation teaching strategies [12]. However, studies investigating the effects of simulation training on workplace violence prevention are still limited. Although prior studies have reported the prevalence of workplace violence $[2,6,7]$ and the effectiveness of prevention training courses in improving workplace violence awareness and reducing violence incidence [15-22], there have been few studies performing comprehensive analysis in studying the effectiveness of violence education and training strategy among nursing staff in Taiwan. This study aimed to investigate the perception of workplace violence and the effectiveness of self-confidence in coping with aggression events through simulation training and education for generalist nurses.

\section{Materials and Methods}

\subsection{Setting and Participants}

In a quasi-experimental study, a total of 66 participants were enrolled via convenience sampling in a nearly 3000-bed national medical center in Taipei, Taiwan. Participants were nursing staff members working in the units with high risk of workplace violence exposure, including emergency departments and medical and surgical wards. Participants were invited to participate in 3-h courses for "simulation education on workplace violence training", and to complete the paper questionnaires both before and immediately after all training courses were completed. The participants were interviewed by using three structured questionnaires, including: (1) basic information; (2) perception of aggression scale (POAS); and (3) confidence in coping with patient aggression.

This study was approved by the Institutional Review Board Taipei Veterans General Hospital (VGHIRB No. 2015-06-007A). The aim of this study, procedures, methodology, and the subject's rights were well explained to the eligible nursing staff according to the informed consent form. Written informed consent was obtained from each participant before data collection.

\subsection{Training Program and Simulation Teaching}

The content design of the "simulation education on workplace violence training" was based on the systematic reviews and nursing staff focus group interviews for framework development of workplace violence training $[10,14,23-25]$. The courses were designed to simulate verbal and physical violence in the real-workplace scenarios, prompting the participants to construct a problem-solving strategy during the learning process and to apply the strategy to the relevant situations.

The details of the courses are shown in Table 1. The teaching elements include the introduction of workplace violence, simulation-based communication, real case and group discussions, videotaped simulations of real case scenario, coping strategy, and discussions after watching the video. The participants were divided into four groups (eight to nine persons in each group) for simulation exercises. A total of two simulation training courses were scheduled. Two expert focus group interviews were arranged to examine the content validity of the courses. 
Table 1. Content of the workplace violence simulation training course.

\begin{tabular}{|c|c|c|c|}
\hline & Content of the Course & Methodology & Duration \\
\hline 1 & $\begin{array}{l}\text { Review of workplace violence prevention } \\
\text { (Recognition of workplace harassment, high-risk } \\
\text { assessment and identification, prevention, coping, } \\
\text { related regulations and physical and } \\
\text { psychological adjustment) }\end{array}$ & Explanation in the classroom & $60 \mathrm{~min}$ \\
\hline 2 & $\begin{array}{c}\text { Workplace violence simulation video (including } \\
\text { verbal and physical violence) }\end{array}$ & Video watching & $10 \mathrm{~min}$ \\
\hline 3 & $\begin{array}{l}\text { Prevention, handling, and communication skills for } \\
\text { verbal abuse }\end{array}$ & $\begin{array}{l}\text { Explanation and demonstration } \\
\text { in the classroom }\end{array}$ & $30 \mathrm{~min}$ \\
\hline 4 & $\begin{array}{l}\text { Prevention, handling, and breakaway skills for } \\
\text { physical violence }\end{array}$ & $\begin{array}{l}\text { Explanation and demonstration } \\
\text { in the classroom }\end{array}$ & $30 \mathrm{~min}$ \\
\hline 5 & $\begin{array}{c}\text { Group simulation exercises and group scenario } \\
\text { review discussion }\end{array}$ & $\begin{array}{l}\text { Simulation, exercise group } \\
\text { discussion, and feedback }\end{array}$ & $50 \mathrm{~min}$ \\
\hline
\end{tabular}

The film was organized based on the real situation, and was shot, edited, and compiled into teaching video according to the principles for simulation design proposed by Jeffries (2007) [26]: (1) introduction; (2) learning objective; (3) case study; and (4) assessment of countermeasures.

\subsection{Study Instruments}

\subsubsection{Baseline Characteristics}

Baseline characteristics of age, gender, education level, marital status, professional title, nursing level, work experience, current unit, current department, seniority, workplace violence experience, etc., were collected for identifying the risk factors for workplace violence (Supplementary Materials).

\subsubsection{Perception of Aggression Scale (POAS)}

The POAS was constructed by Jansen et al. to assess nurses' attitudes toward workplace aggression [27]. The original 32-item POAS was reduced to 12 items by Needham et al. (2004), and consists of two dimensions [28]. The first dimension (Dimension 1) regards violence as a dysfunctional/undesirable phenomenon, and the second dimension (Dimension 2) regards violence as a functional/comprehensible phenomenon, representing negative (Dimension 1) and positive (Dimension 2) perceptions of aggression, respectively. The questionnaire was answered with the five-point Likert scale with good reliability and validity (reliability coefficient $\alpha$ of $r=0.69$ and 0.67 , retest reliability was $r=0.76$ and 0.77 for factors 1 and 2, respectively). The higher scores indicate that the participants had clearer concepts of workplace violence, and the scale is widely used in workplace violence research [28].

\subsubsection{Confidence in Coping with Patient Aggression}

The scale developed by Thackrey is used to measure confidence in dealing with patient aggression [29]. The scale consists of 10 items to be answered using the five-point Likert scale. The higher scores indicate higher confidence in coping with patient aggression. The scale had good $\alpha$ reliability (overall Cronbach's $\alpha: 0.92$ ), and it is widely used in workplace violence studies.

\subsection{Statistical Analyses}

Descriptive analyses were performed for category variables such as gender, education level, marital status, job title and level, work experience, current unit, current department, and workplace violence experience; these variables were described by frequency distribution and percentage. Continuous variables such as age and seniority were described by mean and standard deviation (STD). Differences 
between pre- and post-test performance of workplace violence perception and self-confidence courses were compared using generalized estimating equations (GEE). Data analyses were performed by using the software SPSS for Windows V23.0.

\section{Results}

\subsection{Baseline Characteristics}

The average age of the 66 participants was $32 \pm 9$ years old, most of them were female $(n=58$, $87.9 \%)$, single $(n=44,66.7 \%)$, with a bachelor's degree $(n=57,86.4 \%)$. The majority of participants in this study were registered nurses (RNs, $n=27,40.9 \%$ ) and level-2 nurses (N2s, $n=29,43.9 \%$ ). As for unit types, 29 participants worked in the emergency department (43.9\%) and 37 participants worked in medical and surgical wards $(56.1 \%)$. A total of $44(66.7 \%)$ participants reported that they had experienced workplace violence during nursing work. A total of $40(60.6 \%)$ participants had never received any workplace violence training courses before enrollment, and $58(87.9 \%)$ reported that they would like to receive relevant workplace violence courses and training. The total work experience was $10.1 \pm 8.9$ years on average, and the average current work experience in the medical center was $5.3 \pm 5.2$ years (Table 2 ).

Table 2. Participants' sociodemographic characteristics.

\begin{tabular}{lc}
\hline \multicolumn{1}{c}{ Item } & Total N=66 \\
\hline Age (years) & $32 \pm 9$ \\
Total work experience (years) & $10.1 \pm 8.9$ \\
Seniority (years) & $5.3 \pm 5.2$ \\
\hline Gender & \\
Males & $8(12.1 \%)$ \\
Females & $58(87.9 \%)$ \\
\hline Marital status & \\
Single & $44(66.7 \%)$ \\
Married & $21(31.8 \%)$ \\
Divorced/widowed & $1(1.5 \%)$ \\
\hline Education level & \\
College & $1(1.5 \%)$ \\
University & $57(86.4 \%)$ \\
Graduate school & $8(12.1 \%)$ \\
\hline Job title & \\
Registered profession nurse (RPN) & $20(30.3 \%)$ \\
Registered nurse (RN) & $27(40.9 \%)$ \\
Contract nurse & $19(28.8 \%)$ \\
\hline Nursing level & \\
N & $10(15.2 \%)$ \\
N1 & $9(13.6 \%)$ \\
N2 & $29(43.9)$ \\
N3 & $10(15.2 \%)$ \\
N4 & $8(12.1 \%)$ \\
\hline Work unit & \\
Emergency Department & $29(43.9 \%)$ \\
Medical and surgical wards & $37(56.1 \%)$ \\
\hline Experienced workplace violence & \\
Yes & $44(66.7 \%)$ \\
No & $22(33.3 \%)$ \\
\hline Received a workplace violence training course & \\
Yes & $26(39.4 \%)$ \\
No & $40(60.6 \%)$ \\
\hline Wishes to take workplace violence courses and training & \\
Nes & \\
\hline & \\
\hline & \\
\hline & \\
\hline
\end{tabular}




\subsection{Evaluation of the Outcome of Workplace Violence Simulation Training Course Intervention}

Regarding the pre-test scores, the average score of workplace violence perception (negative) before simulation training intervention was $25 \pm 3$, the attitude (positive) score was $21 \pm 4$, and the confidence in coping skills score was $28 \pm 4$ (Table 3). After simulation training intervention, the post-test score of workplace violence perception (negative) was $26 \pm 3$, the attitude (positive) score was $23 \pm 4$, and the confidence in coping skills score was $32 \pm 5$ (Table 3 ).

Table 3. Scores of workplace violence perceptions and self-confidence in coping with aggression.

\begin{tabular}{ccc}
\hline Items & Pre-Test & Post-Test \\
\hline Attitude-factor 1 (negative) & $25 \pm 3$ & $26 \pm 3$ \\
Attitude-factor 2 (positive) & $21 \pm 4$ & $23 \pm 4$ \\
Confidence in coping skills & $28 \pm 4$ & $32 \pm 5$ \\
\hline
\end{tabular}

In the GEE analyses for comparing the differences between the pre- and post-test performances of workplace violence perceptions, a single variant analysis was firstly carried out for independent variables such as age, gender, marital status, education level, job title, level, work unit, work experience, total work experience, seniority, experience of workplace violence, experience of workplace violence training, and intention to receive workplace violence training. Significant differences were found in marital status, education level, nursing level, experience of workplace violence, and experience of workplace violence training $(p<0.05)$. After multivariable adjustment, post-test performances of factor 1 and factor 2 reached statistical significance $(p<0.001)$, and the score increased by 1.05 and 1.44 points in factors 1 and 2, respectively, as compared to pre-test performances (Table 4). Nursing levels of N2 and N3 were scored as $2.18(p=0.02)$ and $5.09(p<0.001)$ points higher than $\mathrm{N}$, respectively. In addition, the scores of the participants with the experience of violence decreased by 2.45 points compared to the participants without the experience of violence $(p<0.001)$. The scores of the participants with the experience of workplace violence training decreased by 1.58 points compared to the participants without training $(p=0.02)$.

Table 4. Comparison of pre- and post-test of workplace violence perceptions.

\begin{tabular}{lccc}
\hline \multicolumn{1}{c}{ Variable } & Estimated Value & Standard Error & $p$-Value \\
\hline $\begin{array}{l}\text { Attitude-factor 1 (negative) } \\
\quad \text { Post-test vs. Pre-test }\end{array}$ & 1.05 & 0.32 & $<0.001$ \\
\hline $\begin{array}{l}\text { Attitude-factor 2 (positive) } \\
\quad \text { Post-test vs. Pre-test }\end{array}$ & 1.44 & 0.38 & $<0.001$ \\
\hline Marital status & & & \\
$\quad$ Divorce/widowed vs. Single & -2.02 & 1.30 & 0.12 \\
$\quad$ Married vs. Single & -0.10 & 0.81 & 0.90 \\
\hline Education level & & & 0.59 \\
$\quad$ Graduate school (or above) vs. College & -0.79 & 1.45 & 0.88 \\
$\quad$ University vs. College & -0.15 & 1.05 & 0.20 \\
\hline Nursing level & & & 0.02 \\
$\quad$ N1 vs. N & 1.64 & 1.29 & 0.001 \\
N2 vs. N & 2.18 & 0.92 & \\
$\quad$ N3 vs. N & 5.09 & 1.16 & $<0.001$ \\
$\quad$ N4 vs. N & 1.82 & 1.23 & \\
\hline Experience of workplace violence & & & \\
$\quad$ Yes vs. No & -2.45 & 0.77 & \\
\hline Experience of workplace violence training & & & \\
Yes vs. No & -1.58 & 0.69 & \\
\hline
\end{tabular}


In the GEE analyses for confidence in coping skills, significant differences were found in the education level and intention to receive workplace violence training $(p<0.05)$. The GEE analyses revealed a significant increase of 3.94 points in the post-test as compared to the pre-test $(p<0.001$; Table 5). Significant differences were also found in the education level and intention to receive workplace violence training $(p<0.05)$. The scores of the participants who graduated from graduate school (or above) and university level decreased by 5 and 3.92 points, respectively, compared to the participants with college level education (all $p<0.001$ ). The scores of the participants with intention to receive workplace violence training decreased by 2.42 points compared to the participants without the intention to receive training (Table 5).

Table 5. Comparison of pre- and post-test of confidence in coping skills.

\begin{tabular}{lccc}
\hline \multicolumn{1}{c}{ Variable } & Estimated Value & Standard Error & $p$-Value \\
\hline Post-test vs. Pre-test & 3.94 & 0.66 & $<0.001$ \\
\hline Education level & & & $<0.001$ \\
$\quad$ Graduate school (or above) vs. College & -5.00 & 1.27 & $<0.001$ \\
$\quad$ University vs. College & -3.918 & 0.55 & 0.04 \\
\hline $\begin{array}{l}\text { Intention to receive workplace violence training } \\
\quad \text { Yes vs. No }\end{array}$ & -2.42 & 1.15 & \\
\hline
\end{tabular}

\section{Discussion}

This study has several findings, as follow: (1) The "simulation education on workplace violence training" as the intervention significantly improved the workplace violence perception and confidence in coping with aggression events. (2) Higher nursing level was associated with higher scores of workplace violence perception. In contrast, the scores of the participants with prior episodes of workplace violence and workplace violence training experiences were negatively associated with workplace violence perceptions. (3) Significant declines in confidence in coping skills were found in participants with higher education levels and the intention to receive workplace violence training.

Prior studies have provided evidence for prevention training courses improving workplace violence awareness and reducing violence incidence [15-22]. In a systematic review analyzing nine studies on the impact of workplace violence prevention training among nursing staff, all studies reported increased confidence and improved attitude, skills, and knowledge after receiving training [19]. One study discussing workplace violence prevention demonstrated the effectiveness of education and training [23]. Needham et al. (2005) designed a series of violence prevention training courses and suggested that nursing students receiving violence prevention courses had significantly higher self-efficacy and confidence in aggression management as compared to the control group [15]. Lamont and Brunero (2018) demonstrated that overall confidence in coping with workplace violence significantly increased after 78 participants completed the training courses in a tertiary referral hospital in Australia [21]. Moreover, Cook et al. performed a meta-analysis for evaluating the outcomes of simulation training, and reported that simulation training was an effective teaching strategy in terms of knowledge and satisfaction outcomes [30].

Simulation is a participatory experience, helping participants to build their own problem-solving strategies during the learning process, to transform and apply these strategies to relevant situations, and finally to effectively improve their levels of awareness and problem-solving capabilities [12-14]. An integrative review confirmed the efficacy of simulation teaching in nursing education by analyzing 160 articles [14]. A total of $68.1 \%$ studies used simulation teaching and 31.9\% used training skills to develop clinical reasoning. The study reported an improved self-efficacy and self-confidence after simulation teaching. The findings of our study are compatible to the above-mentioned studies, indicating that the "workplace violence simulation training course" is applicable to improve the 
workplace violence-related concepts, which can enhance confidence in coping skills, and can increase confidence in dealing with aggression.

The guideline of the Occupational Safety and Health Administration (OSHA) listed three groups of risk factors that lead to violence in health care, including: (1) clinical factors (e.g., individual pain, altered mental status, history of violence, and the influence of drugs and alcohol); (2) environmental factors (e.g., layout and design of the workspace); and (3) organizational factors (e.g., discouragement to report and difficulty in reporting violent incidents, and lack of staff training and preparedness) [10]. In addition, Magnavita et al. proposed a viewpoint for developing a violence prevention program, and emphasized that the violence prevention can not only be based on clinical or individual measurements, but all educational, organizational, and medical measures are necessary elements in developing the prevention program and reducing violent events [31].

In this study, we found that a total of $66.7 \%$ participants had experienced violent episodes during work, indicating that violent episodes of worker-to-worker or patient-to-worker violence could be very frequent. Magnavita et al. had previously reported an Italian experience that nurses were mostly assaulted or harassed by patients or their relatives, whereas younger nursing students were more frequently exposed to lateral and vertical violence from other healthcare workers [4]. In the current study, we exhibited that the concept scores of workplace violence were higher in the nursing staffs of $\mathrm{N} 3$ and N2 than the junior staffs of $\mathrm{N}$. The reason could be that these groups had more experience in the clinical setting. Therefore, they had more positive attitudes in facing workplace aggression.

For those who had lower scores on workplace violence perceptions, with prior experiences of workplace violence and workplace violence training, we suspected that they may be affected by their previous negative thinking on workplace violence. From the findings of our study, the factors of nursing level, previous exposure to workplace violence, bullying, and previous experience of workplace violence training may affect the training performance. As a result, we should take these factors into detailed and various considerations while propagating or planning workplace violence prevention programs.

- In terms of self-confidence in coping with aggression, our study showed that higher education level was associated with lower confidence. Significantly lower confidence in coping skills was found in nursing staff with graduate or university degrees when compared to those with college degrees. Based on the fact that most of the nurses had their Bachelor's degree, the managers should strengthen their confidence in coping with workplace violence.

\subsection{Limitations, Strengths, and Further Research}

This study is a single-group designed approach focused on the effectiveness of the intervention of "simulation education on workplace violence training" in coping with workplace violence for primary nursing staff in a medical center in Taipei. Meanwhile, since only single pre- and post-tests were conducted in this study, it is not feasible to measure the sustainability of learning effects. In addition, the outcome assessment did not include the follow-up of the occurrences of workplace violence and the actual response skills. In the present study of the intervention of "simulation education on workplace violence training", only basic attributes were analyzed. However, there are still other variables to be discussed, such as whether there were regular environmental hazard assessments in the medical settings, or the assessment of the supervisor's attitude toward the workplace violence incidents. On the other hand, there are many factors affecting the effectiveness of learning, such as different education and training methods, and personal prerequisite knowledge.

This was the first time that our hospital conducted a workplace violence prevention program by applying simulation training. Through 3-h training courses, the nursing staff were provided with required concepts of violence prevention, and significantly improved their concepts of workplace violence prevention and self-confidence in coping strategies. The improvement could be related to the adoption of appropriate teaching strategies: By using the systematic development of classroom courses, the use of audio-visual simulation and practical exercises could strengthen the skills of workplace 
violence prevention. Applying a teaching video for real-case presentation can not only increase the participants' learning interests, but also improve the teaching quality. Besides, both the satisfaction of the course and the extent of understanding were highly evaluated, suggesting that simulation training was a good training strategy for workplace violence prevention.

In the future, we recommended collecting other subjective and objective indicators to be incorporated for the evaluation of workplace violence simulation training program, e.g., the incidences of workplace violence, the attitude of nursing staff to deal with workplace violence, and actual response skills. A clear survey on worker-to-worker/patient-to-worker or lateral/vertical violence should be conducted in the future. In addition, extending the follow-up period to understand the long-term effect of workplace violence simulation training courses could be considered. All the above-mentioned study directions may provide more comprehensive manners to build a high-quality work environment.

\subsection{Clinical Implications}

The results of this study might support the workplace violence simulation training course in the clinical environment. It is also pointed out in the literature that workplace violence prevention programs reduce the exposure of workplace violence behaviors, which in turn reduce the psychological distress of employees, and has a positive impact on the overall quality of life and working style of employees [32]. It is recommended to develop different simulations for specific medical units in the future, such as emergency, psychiatric, maintenance institutions, home care, internal medicine wards, surgery wards and outpatient clinics. Also recommended is to integrate simulation training into the regular workplace violence prevention program of the hospital, and to update the program periodically to meet the latest needs. In the future, an online course on workplace violence prevention can be developed to facilitate more flexible learning through text, real-case videos, and interactive processes, for nursing staff to learn the prevention strategies online and practice in the real-world simulation training courses.

\section{Conclusions}

In this study, we constructed the "Workplace Violence Simulation Training Course" and investigated the training effects on the concepts of workplace violence and self-confidence in coping strategies. We concluded that significant increases in post-test scores for both perception of workplace violence and confidence against aggression events were found, indicating simulation education can improve the concepts of workplace violence and confidence in dealing with violent events.

Here, we put forward the following recommendations based on our study findings for consideration: (1) planning of a workplace violence prevention program which might incorporate simulation teaching and practice, in order to provide real-world experiences of learning and coping skills, and to increase learning interest and motivation; (2) developing and adjusting the medical unit-specific simulation training courses and integrated simulation trainings into the regular workplace violence prevention program; and (3) developing an online course based on the workplace violence prevention program to facilitate more flexible learning.

Supplementary Materials: The following are available online at http://www.mdpi.com/1660-4601/16/19/3648/s1, Supplementary Material: Questionnaires.

Author Contributions: Data curation, C.-I.C.; Methodology, S.-P.H.; Project administration, Y.-S.H.; Resources, Y.-M.T.; Supervision, J.-L.M.; Validation, H.-Y.H.; Visualization, T.-F.H.; Writing—original draft, H.-M.H.

Funding: This research received no external funding.

Acknowledgments: The authors would like to acknowledge Taipei Veterans General Hospital for the support of this study (program number: V104EA-006), and the authors also deeply appreciate all the nursing staff participating in this study.

Conflicts of Interest: The authors declare no conflict of interest. 


\section{References}

1. Spector, P.E.; Zhou, Z.E.; Che, X.X. Nurse exposure to physical and nonphysical violence, bullying, and sexual harassment: A quantitative review. Int. J. Nurs. Stud. 2014, 51, 72-84. [CrossRef] [PubMed]

2. Nelson, R. Tackling violence against health-care workers. Lancet 2014, 383, 1373-1374. [CrossRef]

3. Hinchberger, P.A. Violence against female student nurses in the workplace. Nurs. Forum 2009, 44, 37-46. [CrossRef] [PubMed]

4. Magnavita, N.; Heponiemi, T. Workplace violence against nursing students and nurses: An Italian experience. J. Nurs. Scholarsh. 2011, 43, 203-210. [CrossRef] [PubMed]

5. Ferri, P.; Silvestri, M.; Artoni, C.; Di Lorenzo, R. Workplace violence in different settings and among various health professionals in an Italian general hospital: A cross-sectional study. Psychol. Res. Behav. Manag. 2016, 9, 263-275. [CrossRef] [PubMed]

6. Ramacciati, N.; Ceccagnoli, A.; Addey, B.; Lumini, E.; Rasero, L. Violence towards emergency nurses: A narrative review of theories and frameworks. Int. Emerg. Nurs. 2018, 39, 2-12. [CrossRef] [PubMed]

7. Yenealem, D.G.; Woldegebriel, M.K.; Olana, A.T.; Mekonnen, T.H. Violence at work: Determinants \& prevalence among health care workers, northwest Ethiopia: An institutional based cross sectional study. Ann. Occup. Environ. Med. 2019, 31, 8. [PubMed]

8. Richards, J. Protecting Health Workers from Exposure to Occupational Violence. In Joint Programme on Workplace Violence in the Health Sector: International Labour Office, International Council of Nurses; World Health Organisation, Public Services Internationall: Geneva, Switzerland, 2003.

9. Wand, T.; Coulson, K. Zero tolerance: A policy in conflict with current opinion on aggression and violence management in health care. Australas. Emerg. Nurs. J. 2006, 9, 163-170. [CrossRef]

10. Arbury, S.; Hodgson, M.; Zankowski, D.; Lipscomb, J. Workplace Violence Training Programs for Health Care Workers: An Analysis of Program Elements. Workplace Health Saf. 2017, 65, 266-272. [CrossRef] [PubMed]

11. Najafi, F.; Fallahi-Khoshknab, M.; Ahmadi, F.; Dalvandi, A.; Rahgozar, M. Antecedents and consequences of workplace violence against nurses: A qualitative study. J. Clin. Nurs. 2018, 27, e116-e128. [CrossRef]

12. Bland, A.J.; Topping, A.; Wood, B. A concept analysis of simulation as a learning strategy in the education of undergraduate nursing students. Nurse Educ. Today 2011, 31, 664-670. [CrossRef] [PubMed]

13. Park, H.-R.; Park, J.-W.; Kim, C.-J.; Song, J.-E. Development and validation of simulation teaching strategies in an integrated nursing practicum. Collegian 2017, 24, 479-486. [CrossRef]

14. Almeida, R.; Jorge, B.M.; Souza-Junior, V.D.; Mazzo, A.; Martins, J.C.A.; Negri, E.C.; Mendes, I.A.C. Trends in Research on Simulation in the Teaching of Nursing: An Integrative Review. Nurs. Educ. Perspect 2018, 39, E7-E10. [CrossRef] [PubMed]

15. Needham, I.; Abderhalden, C.; Zeller, A.; Dassen, T.; Haug, H.J.; Fischer, J.E.; Halfens, R.J. The effect of a training course on nursing students' attitudes toward, perceptions of, and confidence in managing patient aggression. J. Nurs. Educ. 2005, 44, 415-420. [PubMed]

16. Gerdtz, M.F.; Daniel, C.; Dearie, V.; Prematunga, R.; Bamert, M.; Duxbury, J. The outcome of a rapid training program on nurses' attitudes regarding the prevention of aggression in emergency departments: A multi-site evaluation. Int. J. Nurs. Stud. 2013, 50, 1434-1445. [CrossRef]

17. Gillespie, G.L.; Farra, S.L.; Gates, D.M. A workplace violence educational program: A repeated measures study. Nurse Educ. Pract. 2014, 14, 468-472. [CrossRef]

18. Kotora, J.G.; Clancy, T.; Manzon, L.; Malik, V.; Louden, R.J.; Merlin, M.A. Active shooter in the emergency department: A scenario-based training approach for healthcare workers. Am. J. Disaster Med. 2014, 9, 39-51. [CrossRef]

19. Heckemann, B.; Zeller, A.; Hahn, S.; Dassen, T.; Schols, J.M.; Halfens, R.J. The effect of aggression management training programmes for nursing staff and students working in an acute hospital setting. A narrative review of current literature. Nurse Educ. Today 2015, 35, 212-219. [CrossRef]

20. Ramacciati, N.; Ceccagnoli, A.; Addey, B.; Lumini, E.; Rasero, L. Interventions to reduce the risk of violence toward emergency department staff: Current approaches. Open Access Emerg. Med. 2016, 8, 17-27. [CrossRef]

21. Lamont, S.; Brunero, S. The effect of a workplace violence training program for generalist nurses in the acute hospital setting: A quasi-experimental study. Nurse Educ. Today 2018, 68, 45-52. [CrossRef]

22. Rutherford, D.E.; Gillespie, G.L.; Smith, C.R. Interventions against bullying of prelicensure students and nursing professionals: An integrative review. Nurs. Forum 2019, 54, 84-90. [CrossRef] [PubMed] 
23. McPhaul, K.M.; London, M.; Lipscomb, J.A. A framework for translating workplace violence intervention research into evidence-based programs. Online J. Issues Nurs. 2013, 18, 4. [PubMed]

24. Hartley, D.; Ridenour, M.; Craine, J.; Morrill, A. Workplace violence prevention for nurses on-line course: Program development. Work 2015, 51, 79-89. [CrossRef] [PubMed]

25. Ming, J.L.H.H.M.; Hong, S.P.; Tseng, L.H.; Huang, M.S.; Chiang, S.H.; Tung, C.Y. A systematic review of workplace violence in nursing. Taiwan J. Public Health 2016, 35, 116-135.

26. Jeffries, P.R. Simulation in Nursing Education: From Conceptualization to Evaluation; National League for Nursing: New York, NY, USA, 2007.

27. Jansen, G.; Dassen, T.; Moorer, P. The Perception of Aggression. Scand. J. Caring Sci. 1997, 11, 51-55. [CrossRef] [PubMed]

28. Needham, I.; Abderhalden, C.; Dassen, T.; Haug, H.J.; Fischer, J.E. The perception of aggression by nurses: Psychometric scale testing and derivation of a short instrument. J. Psychiatr. Ment. Health Nurs. 2004, 11, 36-42. [CrossRef] [PubMed]

29. Thackrey, M. Clinician confidence in coping with patient aggression: Assessment and enhancement. Prof. Psychol. Res. Pract. 1987, 18, 57-60. [CrossRef]

30. Cook, D.A.; Hamstra, S.J.; Brydges, R.; Zendejas, B.; Szostek, J.H.; Wang, A.T.; Erwin, P.J.; Hatala, R. Comparative effectiveness of instructional design features in simulation-based education: Systematic review and meta-analysis. Med. Teach. 2013, 35, e867-e898. [CrossRef]

31. Magnavita, N. Violence prevention in a small-scale psychiatric unit: Program planning and evaluation. Int. J. Occup. Environ. Health 2011, 17, 336-344. [CrossRef]

32. Guay, S.; Goncalves, J.; Boyer, R. Evaluation of an Education and Training Program to Prevent and Manage Patients' Violence in a Mental Health Setting: A Pretest-Posttest Intervention Study. Healthcare 2016, 4, 49. [CrossRef]

(C) 2019 by the authors. Licensee MDPI, Basel, Switzerland. This article is an open access article distributed under the terms and conditions of the Creative Commons Attribution (CC BY) license (http://creativecommons.org/licenses/by/4.0/). 